\title{
Atividade experimental como recurso para interação de alunos com transtornos específicos de aprendizagem em Física Moderna e Contemporânea
}

Eduardo Lemes Monteiro emonteiromat@hotmail.com 0000-0001-8222-1728 Universidade Tecnológica Federal do Paraná, Paraná, Brasil.

Paulo Sérgio de Camargo Filho paulocamargo@utfpr.edu.br 0000-0002-2407-4878

Universidade Tecnológica Federal do Paraná, Paraná, Brasil.

Marcella Cristyanne Comar Gresczysczyn

marcella.comar@gmail.com

0000-0003-3374-287-

Universidade Tecnológica Federal do

Paraná, Paraná, Brasil.

\section{RESUMO}

A aprendizagem é um processo complexo que depende de fatores orgânicos e comportamentais. Dessa forma, conhecer a origem dos distúrbios de aprendizagem que comprometeram a assimilação do conhecimento é importante. Neste trabalho será enfatizada a discussão sobre a dislexia, um distúrbio de aprendizagem a qual acarreta dificuldades no desenvolvimento das habilidades de leitura e escrita. Os alunos disléxicos apresentam peculiaridades no processo de ensino e o professor deve promover práticas pedagógicas adequadas para que esses tenham equidade no processo de ensino. Percebendo a importância da disciplina de Física Moderna no currículo de Física no Ensino Médio, propõe-se neste trabalho uma atividade experimental, confeccionada com materiais de baixo custo, cuja abordagem será o efeito fotoelétrico. Ao trabalhar o experimento, o professor pode incentivar os alunos com dislexia a investigarem o que ocorre no decorrer de sua execução e, por meio de perguntas, levá-los a expressar as suas ideias prévias na tentativa de explicarem o seu funcionamento.
\end{abstract}

PALAVRAS-CHAVE: Física. Dislexia. Experimento. Efeito fotoelétrico. 


\section{INTRODUÇÃO}

Nos últimos anos muitos educadores de escolas públicas brasileiras têm se surpreendido com a presença de alunos com deficiências matriculados no ensino regular, em diferentes níveis de ensino. A partir disso, conforme consta no senso escolar do Ministério da Educação, o número de adolescentes com deficiência teve um significativo aumento passando de 42.499 alunos matriculados no Ensino Médio em 2012 para 56.976 matriculados em 2015.

Diante dessa realidade no âmbito escolar surgem questionamentos pautáveis com respostas ineficazes. Dentre muitos, há um que se desperta paulatinamente entre a sociedade como um todo; como por exemplo, o direito ao atendimento educacional especial previsto ou não pela lei aos portadores de dislexia. Alguns pontos consideráveis podem ser retomados para que haja uma melhor reflexão acerca do assunto em pauta.

Primeiramente, foi através da Carta Magna, lei maior de uma sociedade política, em 1988, que a Constituição Federal prescreveu no seu artigo 208, inciso III, o "atendimento educacional especializado aos portadores de deficiência, preferencialmente na rede regular de ensino", sendo esse um dever entre as atribuições do Poder Público e do Estado. Dessa forma o disléxico não será contemplado pela lei, pois é portador de uma dificuldade e não de uma deficiência.

Significativos avanços no dispositivo da Constituição de 1988 foram necessários para assegurar aos "portadores de deficiências" um atendimento especializado na rede regular de ensino. Porém, recuos jurídicos se fizeram presentes por meio da terminologia em destaque que se deu ao final dos anos 80 devido ao conceito de deficiência ser considerado herança da medicina de séculos anteriores. Época esta, em que o Brasil excludente tratava seus doentes usando esse termo para deficientes ou não, como "portadores de moléstia infecciosa", cujo enfoque clínico perdurou até a Constituição Federal de 1988.

Abaixo hierarquicamente no ordenamento jurídico do país, a Lei de Diretrizes e Bases da Educação LDB (BRASIL, 1996) será responsável pela troca da terminologia "portadores de deficiência" para "educandos com necessidades educacionais especiais". A LDB (Lei de Diretrizes e Bases da Educação) mediante a Lei 9.394/94, juntamente com a Constituição Federal de 1988 e a legislação do Conselho Nacional de Educação amparam os educandos que apresentam dificuldades de aprendizagem relacionadas à linguagem tais como: dislexia, disgrafia e disortografia. Vale lembrar que a partir desse momento os disléxicos são caracterizados perante a lei como portadores de necessidades educacionais especiais e que também necessitam de atendimento específico na área de leitura.

Essas dificuldades de aprendizagem abrangem uma diversidade de necessidades educacionais associadas aos problemas psicolinguísticos (dislexia e disfunções correlatas), psicomotores, motores, cognitivos (atenção, concentração, percepção, memória), à hiperatividade e ainda aos fatores ambientais e socioeconômicos. $O$ estado brasileiro, por sua vez, passa a garantir e assumir constitucionalmente o compromisso de educar a todos sem qualquer discriminação ou exclusão social garantindo aos 
educandos o acesso ao ensino fundamental. Estabelecido como um direito público inalienável, ele ampara os adolescentes em processo escolar independentemente de se caracterizarem como especiais ou não.

Isto posto, Martins (2004) destaca na Lei de Diretrizes da Educação Nacional (BRASIL 1996), artigo 40, inciso III, o dever do Estado para com a educação escolar pública: "atendimento educacional especializado gratuito aos educandos com necessidades especiais, preferencialmente na rede regular de ensino".

A matrícula de todos os educandos com necessidades especiais foi assegurada com o Parecer CNE/CEB n. $\cong$ 17/2001, de 03 de julho de 2001 e a Resolução CNE/CEB n. 02, de 11 de setembro de 2001. Esta última descreve como serão reconhecidos esses educandos com necessidades especiais:

Art. 50 Consideram-se educandos com necessidades educacionais especiais os que, durante o processo educacional, apresentarem:

I - dificuldades acentuadas de aprendizagem ou limitações no processo de desenvolvimento que dificultem o acompanhamento das atividades curriculares, compreendidas em dois grupos:

a) aquelas não vinculadas a uma causa orgânica específica;

b) aquelas relacionadas a condições, disfunções, limitações ou deficiências:

II - dificuldades de comunicação e sinalização diferenciadas dos demais alunos, demandando a utilização de linguagens e códigos aplicáveis;

III - altas habilidades/superdotação, grande facilidade de aprendizagem que os leve a dominar rapidamente conceitos, procedimentos e atitudes. (Resolução CNE/CEB n.ㅇ 02, de 11 de setembro de 2001, p. 2, 2001)

Partindo desse pressuposto, as crianças e adolescentes com dislexia se enquadram no grupo de educandos com dificuldades específicas no aprendizado da leitura sendo este o foco desse trabalho. Os alunos, agora inseridos na sala regular de ensino, necessitam de um apoio e acompanhamento pedagógico provenientes do professor que os auxiliará no desenvolvimento cognitivo levando-os ao processo de ensinoaprendizagem com êxito, de responsabilidades de todas as áreas de conhecimento.

Para ensinar os disléxicos, conforme orientam Braggio e Borba (2008), é necessário que os ensine a resolver conflitos de opiniões. Obter uma ação construtiva, mostrar liderança e chegar a um denominador comum, é preciso transformar a sala de aula em uma oficina, onde eles possam exercitar seu raciocínio. Sendo assim, cabe ao professor mediar esse conhecimento para que o ensino seja realmente eficaz e suficiente para melhorar o conhecimento do aluno e auxiliado no seu desenvolvimento.

O ensino de Física no Ensino Médio, como o de outras disciplinas, é direcionado através de documentos oficiais que discutem acerca dos conteúdos, metodologias e temas importantes para nortear o ensino. Com base nisso, os PCNs (Parâmetros Curriculares Nacionais para o Ensino Médio) referem-se à Física como sendo uma área de conhecimento que envolve competências que permitem aos educandos perceber e lidar com 
fenômenos naturais, científicos e tecnológicos, presentes em seu cotidiano e em todo o mundo, bem como conhecimentos que envolvam a cultura, resolução de problemas e responsabilidade social. Segundo os PCNs, os aspectos da Física Moderna são essenciais para uma compreensão sobre a matéria e o mundo microscópico, conhecimentos estes essenciais para um entendimento de diferentes e novos materiais, o desenvolvimento da tecnologia e as radiações e suas aplicações. De acordo com o mesmo documento a importância deste conteúdo é elevada devido ao cotidiano contemporâneo que está em constante evolução, com tecnologias baseadas na microtecnologia e nas formas de radiações, podendo entender como procedem e os riscos e benefícios dessas aplicações.

Para além da importância que os temas da Física Moderna e Contemporânea apresentam nos currículos escolares, também deve ser pensado em metodologias que permitam um entendimento por parte dos estudantes, que desperte o seu interesse e a curiosidade, gerando assim um processo de ensino aprendizagem satisfatório. Para Moreira (2004, p.5), "[...] A Física é considerada, na escola, uma matéria difícil, pouco motivadora, aprendida mecanicamente [...]". Para tornar a aprendizagem possível para todos os alunos, ou por grande parte deles, o ponto de partida deveria explorar vários métodos e abordagens. No caso deste trabalho em que se aborda o conteúdo de partículas elementares, pretende-se trabalhar com multimodos e múltiplas representações para o ensino de Física. O emprego da multiplicidade de formas e modos de representação durante o ensino é uma condição indissociável, visto que quando se trabalha com diversas técnicas e atividades explorando os variados meios de cognição, facilidades e dificuldades dos alunos, se consegue alcançar uma maior totalidade do aprendizado.

\section{FUNDAMENTAÇÃO TEÓRICA}

\subsection{Dislexia e Inclusão}

Dislexia é um termo usado para se referir à criança ou ao adolescente que apresenta dificuldade para ler e consequentemente para escrever. Levando em conta que a leitura é consequência da escrita, a criança com dislexia também não escreve e não lê bem.

Para lanhes (1994), dislexia é um dos muitos distúrbios de aprendizagem caracterizada pela dificuldade de decodificação das palavras simples, mostrando uma insuficiência no processamento fonológico. Essas dificuldades na decodificação de palavras simples não são esperadas em relação à idade; apesar da instrução convencional. Adequada inteligência, oportunidade sociocultural e ausência de distúrbios cognitivos e sensoriais, a criança falha no processo da aquisição da linguagem com frequência, incluindo os problemas de leitura, aquisição e capacidade de escrever e soletrar.

$O$ adolescente com dislexia tem por si só uma autoestima baixa, julgase incapaz, portanto necessita da ajuda de profissionais capacitados para superar seus medos, suas frustrações, insegurança aos poucos ou então, logo haverá evasão escolar. Sendo assim, cabe à escola e ao professor 
mediar esse conhecimento, ciente que a dislexia tem vários níveis e grupos cada qual com sua especificidade deverá receber o devido tratamento sugerido por um especialista seja psicólogo, fonoaudiólogo ou outros.

O termo dislexia é alvo de pesquisa em períodos anteriores. Para Rotta e Pedroso (2007), em 1872, Berlin mencionou o termo pela primeira vez, posteriormente foi utilizado por Kerr. No ano de 1896 publicou, no Britian Medical Journal, o interessante caso de um adolescente com incapacidade para ler, contudo, cognitivamente deveria ter condições de fazer.

Em 1994, a UNESCO realizou a "Conferência Mundial sobre Educação para Todos" realizada em Jomtien, Tailândia. Esta conferência iniciou um grande projeto de educação em nível mundial, e tinha como principal eixo a ideia da "satisfação das necessidades básicas de aprendizagem". Participaram desta reunião cerca de 160 representantes de diversos governos. Estes por sua vez se comprometeram a assegurar uma "educação básica de qualidade" a crianças, jovens e adultos. Diversas agências internacionais, organizações não governamentais, associações profissionais e destacadas personalidades na área da educação em nível mundial, compareceram, também, a conferência. Um dos feitos mais marcantes da conferência em questão foi a elaboração da seguinte declaração:

\footnotetext{
Cada pessoa - criança, jovem ou adulto - deverá estar em condições de aproveitar as oportunidades educacionais oferecidas para satisfazer suas necessidades básicas de aprendizagem. Estas necessidades abarcam tanto as ferramentas essenciais para a aprendizagem (como a leitura e a escrita, a expressão oral, o cálculo, a solução de problemas) como os conteúdos básicos da aprendizagem (conhecimentos teóricos e práticos, valores e atitudes) necessários para que os seres humanos possam sobreviver, desenvolver plenamente suas capacidades, viver e trabalhar com dignidade, participar plenamente do desenvolvimento, melhorar a qualidade de sua vida, tomar decisões fundamentais e continuar aprendendo. A amplitude das necessidades básicas de aprendizagem varia de país a país em sua cultura e muda inevitavelmente com o transcurso do tempo. (UNESCO, 1994A, p. 157).
}

Depois dessa reunião, foi formada uma comissão Internacional sobre Educação para o Século XXI, que tinha como função produzir um relatório contendo um diagnóstico do "contexto planetário de interdependência e globalização". Evidenciando o desemprego e a exclusão social, mesmo em países ricos. O relatório fez recomendações de conciliação, consenso, cooperação, solidariedade para enfrentar as tensões da mundialização, a perda das referências e de raízes, as demandas de conhecimento científico tecnológico, principalmente das tecnologias de informação. A educação seria o instrumento fundamental para desenvolver nos indivíduos a capacidade de responder a esses desafios, particularmente a educação média. Sugere ainda a educação continuada e a certificação dos conhecimentos adquiridos 
A partir desse relatório o banco mundial adotou as conclusões da Conferência, elaborando diretrizes políticas para as décadas subsequentes a 1990. Em 1994 foi publicada a declaração de Salamanca. Esta por sua vez tinha como objetivo garantir o direito e o acesso de todos à educação tendo como princípio orientador adotado segundo consta a seguir:

\begin{abstract}
Todas as escolas deveriam acomodar todas as crianças independente de suas condições físicas, intelectuais, sociais, emocionais, linguísticas ou outros. Deveriam incluir crianças deficientes e superdotadas, crianças de rua e que trabalham, crianças de origem remota ou de população nômade, crianças pertencentes a minorias linguísticas, étnicas ou culturais e crianças de outros grupos em desvantagem ou marginalizados. No contexto destas linhas de ação o termo "necessidades educacionais especiais" refere-se a todas aquelas crianças ou jovens cujas necessidades se originam em função de deficiências ou dificuldades de aprendizagem. Muitas crianças experimentam dificuldades de aprendizagem e têm, portanto, necessidades educacionais especiais em algum momento de sua escolarização. As escolas têm que encontrar a maneira de educar com êxito todas as crianças, inclusive as que têm deficiências graves. Declaração de Salamanca. (UNESCO, 1994)
\end{abstract}

Em outras palavras devem-se oferecer condições para que todos possam ter as mesmas possibilidades e responsabilidades. Como os alunos são diferentes entre si, para que seja possível conseguir tais condições torna-se necessário adotar condutas desiguais de ação entre as pessoas. Dentro desta ótica, a adoção de um sistema único de integração seria um erro uma vez que cada aluno, dependendo de sua personalidade, dificuldade e contexto social, reagirá de forma diferenciada ao conteúdo escolar.

\title{
1.2 Interagindo com a Física Moderna e Contemporânea
}

Partindo das orientações dos Parâmetros Curriculares Nacionais (PCN), o mesmo salienta que o ensino da Física Moderna deve remeter a um contato que pareça familiar ao aluno, ou seja, que tenha relação com seu cotidiano e as transformações científicas e tecnológicas que se observa no mundo, podendo os conteúdos servir de objetos de estudo para resoluções de problemas que possam intrigá-los, e a partir do ensino de Física se crie sínteses e compreensões consistentes dos elementos envolvidos nesse estudo.

Outro documento que norteia o ensino de Física são as Diretrizes Curriculares Estaduais para o Ensino de Física (DCEs), neste é perceptível à importância que a Física Quântica recebe, discutindo a cerca de que a Física Clássica nem sempre é suficiente para explicar alguns conceitos, "[...] o modelo do átomo de Bohr é suficiente. Por outro lado, no âmbito da Física de Partículas, esse modelo não é aconselhável [...]" SEED (2013, p.67). Discorrendo sobre a necessidade que tem de fazer ligações com a Física Moderna, podendo assim acompanhar as evoluções que a ciência passa, e dessa forma ter uma compreensão mais coerente dos fenômenos físicos e suas relações com nosso ambiente. 
É importante considerar que para que a aprendizagem seja alcançada é necessário que os alunos tenham interesse pelo assunto abordado, que se motivem a estudar e compreender os fenômenos relativos ao conteúdo em questão. Como Aloi, Haydu e Carmo (2014) "para tornar um estudante motivado a estudar, considera-se como fundamental o arranjo das contingências da escola do ambiente da escola" sendo assim necessário que o aluno sinta o ambiente escolar como parte relativa de seu sujeito. Dessa forma a cultura e o meio em que os sujeitos estejam inseridos são pontos a serem considerados no que remete o planejamento e aplicação dos conteúdos e atividades, pois com isso pode-se criar um engajamento maior dos estudantes na realização das tarefas, discussão dos assuntos e temas pertinentes ao conteúdo.

Considerando-se a importância da inserção da Física Moderna e Contemporânea no currículo de Física do Ensino Médio, Da Silva e Assis (2012) propõe uma atividade experimental confeccionada com materiais de baixo custo, que aborda o efeito fotoelétrico. Para eles, essa atividade pode ser utilizada de forma contextualizada, articulando-se esse fenômeno com algumas aplicações tecnológicas vivenciadas pelos alunos no seu cotidiano. Conforme os autores, ao trabalhar o experimento, o professor pode incentivar os alunos a investigarem o que ocorre no decorrer de sua execução e, por meio de perguntas, levá-los a expressar as suas ideias prévias na tentativa de explicarem o seu funcionamento. Essa articulação vinculada à interação social em sala de aula pode despertar a curiosidade e a motivação dos alunos em aprenderem os conhecimentos trabalhados.

\section{PROCEDIMENTOS METODOLÓGICOS}

A amostra, foco desta investigação, constituiu-se de alunos com transtornos específicos de aprendizagem (dislexia), oficialmente diagnosticados e acompanhados por um docente responsável pela aplicação das atividades. Os alunos pertencem a uma escola pública que abrange Ensino Fundamental II e Médio no estado do Paraná. Durante as aulas propomos abordar o conteúdo efeito fotoelétrico com ênfase no caráter da dualidade onda-partícula. Esse procedimento foi executado em três aulas de 45 minutos cada, com 7 momentos distintos.

Para contemplar as atividades didáticas e experimentais ao longo da proposta desenvolvemos uma sequência de aulas integrando sugestões didáticas derivadas de pesquisas contemporâneas sobre processo de ensino-aprendizagem de conceitos científicos. Para uma posterior investigação mais detalhada do processo de aprendizagem ao longo da instrução laboratorial, associamos o recurso utilizado, os objetivos de cada atividade e tempo necessário para tal.

No processo de coleta de dados para o estudo presente nesta pesquisa recorremos a técnicas próprias da investigação qualitativa: a produção escrita, gravação em vídeo, observação e entrevista. Por esse motivo, cada estudante deve manter um arquivo pessoal organizado com todas as representações científicas produzidas ao longo das aulas.

Tabela 1 - Síntese das Atividades. 


\begin{tabular}{|c|c|c|c|}
\hline Aula & Recurso Didático & Objetivo & $\begin{array}{c}\text { Tempo } \\
\text { (min) }\end{array}$ \\
\hline 1 & $\begin{array}{l}\text { Vídeo } \\
\text { https://www.youtube. } \\
\text { com/watch?v=7ZuOKg } \\
\text { y6hzc }\end{array}$ & $\begin{array}{l}\text { Imersão no tema } \\
\text { e discussão inicial }\end{array}$ & 30 \\
\hline I & $\begin{array}{l}\text { Multimídia Interativo } \\
\text { (slide) }\end{array}$ & $\begin{array}{l}\text { Exposição dos } \\
\text { aspectos } \\
\text { históricos }\end{array}$ & 15 \\
\hline II & $\begin{array}{l}\text { Multimídia } \\
\text { Interativo } \\
\text { (simulador) } \\
\text { https://phet.colorado. } \\
\text { edu/pt_BR/simulation/ } \\
\text { legacy/photoelectric }\end{array}$ & $\begin{array}{l}\text { Visualizar e } \\
\text { interagir com a } \\
\text { experiência do } \\
\text { efeito fotoelétrico }\end{array}$ & 30 \\
\hline II & $\begin{array}{l}\text { Dinâmica dos gêneros } \\
\text { discursivos: dialógico e } \\
\text { univocal. }\end{array}$ & $\begin{array}{l}\text { Organizar e } \\
\text { refinar as } \\
\text { concepções } \\
\text { científicas dos } \\
\text { alunos }\end{array}$ & 15 \\
\hline III & $\begin{array}{l}\text { Concepção do } \\
\text { Experimento }\end{array}$ & $\begin{array}{l}\text { Separação e } \\
\text { familiarização } \\
\text { com os materiais. }\end{array}$ & 15 \\
\hline III & $\begin{array}{l}\text { Montagem do } \\
\text { Experimento }\end{array}$ & $\begin{array}{l}\text { Organização da } \\
\text { sequência de } \\
\text { montagem. }\end{array}$ & 15 \\
\hline III & $\begin{array}{l}\text { Finalização do } \\
\text { Experimento }\end{array}$ & $\begin{array}{l}\text { Observação do } \\
\text { efeito e } \\
\text { discussão. }\end{array}$ & 15 \\
\hline
\end{tabular}

Fonte: Elaborado pelo autor.

\section{Detalhamento do experimento "Ouça seu controle remoto!"}

Para Da Silva e Assis (2012) o experimento tem um apelo lúdico, uma vez que permite aos alunos ouvir o ruído que um circuito produz ao receber o sinal de um controle remoto. Esse fenômeno pode levar os alunos a se sentirem curiosos e até desconfiados, pois o referido ruído de um controle remoto não é algo que acontece no cotidiano. Essas emoções despertadas nos alunos podem ser utilizadas positivamente pelo professor.

Os materiais necessários para a montagem do experimento podem ser adquiridos em uma loja de componentes eletrônicos. A relação de materiais para a montagem do experimento, ilustrado na Figura 1 corresponde a: 1 bateria de 9 V; 1 LDR; 1 LED vermelho (ou de outra cor); 1 resistor de $680 \Omega$ e $1 / 8 \mathrm{~W} ; 1$ suporte para bateria; 1 controle remoto comum de televisão; 1 conjunto de caixas de som de computador ou de rádio, ou alto-falante de carrinho de brinquedo. 


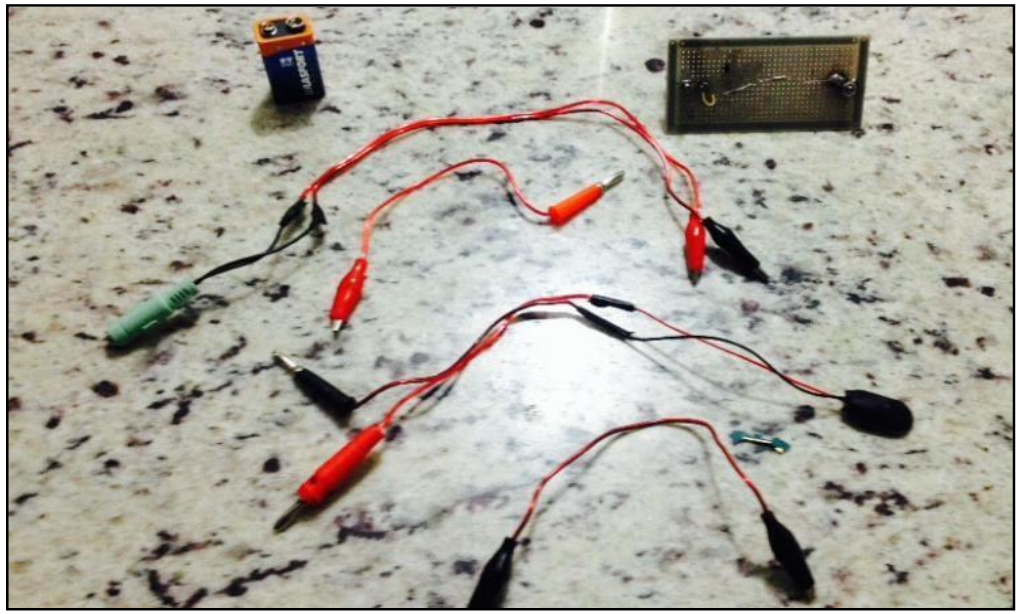

(Fonte: Elaborada pelo autor, 2015)

Para a sua montagem, primeiramente é preciso verificar a polaridade do LED (não há polaridade no LDR). Como o LED é um diodo, ele conduz a corrente elétrica apenas em um único sentido. Ao comprar o LED, você perceberá que uma das "perninhas" é ligeiramente maior que a outra. Esse é o polo positivo do componente e deve ser ligado ao polo positivo da bateria. A montagem do experimento está representada na Figura 2:

Figura 2 - Circuito envolvendo o resistor, a bateria, o LDR e o LED - Lado A

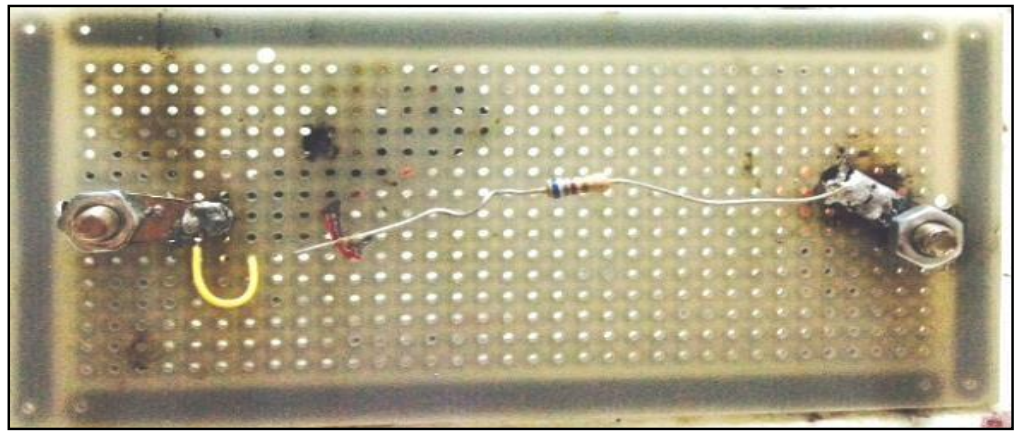

(Fonte: Elaborada pelo autor, 2015)

A bateria, o LDR, o LED e o resistor são ligados em série nessa ordem (observar o circuito ilustrado na Figura 2). Com os jacarés, liga-se o pino fêmea P2 em paralelo com o resistor. É através do resistor que escutaremos o som do sinal do controle remoto. Esse som é gerado devido à variação de ddp obtida no resistor, que é a mesma da caixinha de som, pois ela está ligada em paralelo com esse resistor. Essa variação de ddp é resultado da alteração da corrente elétrica no circuito, provocada pela alteração da resistência do LDR ao ser atingido pelo infravermelho pulsado do controle remoto. 
Figura 3: Circuito - Lado B

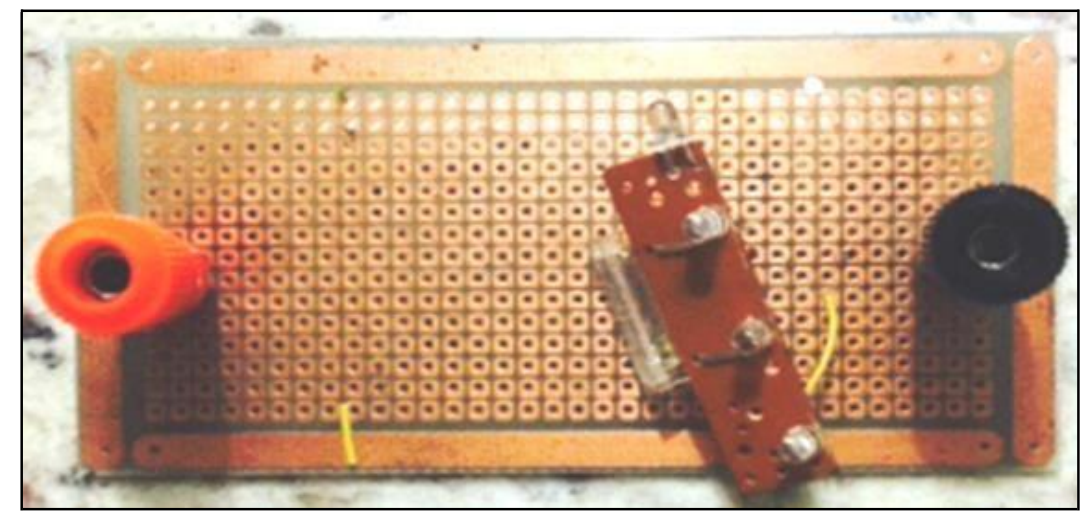

(Fonte: Elaborada pelo autor, 2015)

Para testar o funcionamento do circuito, basta iluminar o LDR com um laser. Se o LED acender, é porque está tudo conectado corretamente. Senão, verifique as ligações e a polaridade do LED. Pode ser que a polaridade foi trocada ou que algum fio não esteja ligado de forma adequada. Para testar a saída de som do alto-falante ao circuito (Figura 4), usa-se um controle remoto de televisão.

Figura 4: Alto-falante conectado ao circuito

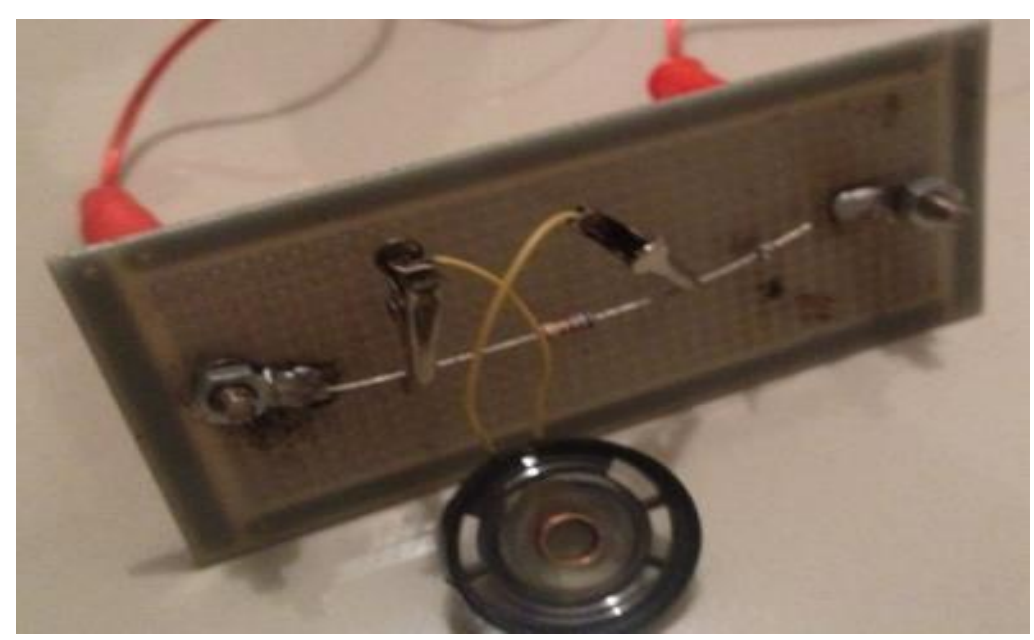

(Fonte: Elaborada pelo autor, 2015)

Se tudo estiver bem conectado, o som do controle remoto semelhante ao som de um helicóptero será ouvido, devido ao fato de o infravermelho do controle ser pulsado. O circuito pode ser montado sobre um papelão duro utilizando-se fios de ligação e fita isolante ou solda para conectar cada elemento ao circuito. 


\section{CONSIDERAÇÕES FINAIS}

Entende-se esse modelo de ensino-aprendizagem como um incentivo a uma acentuada participação por parte dos alunos; ao passo que sendo visível e palpável, frente à disciplina de Física e seus conteúdos, tudo ganhe mais sentido, pois partirá do real, do concreto e não ficará retido apenas à explanação teórica. Além disso, poderão expor suas potencialidades ao elaborar e finalizar $o$ experimento desenvolvendo habilidades motoras e racionais.

Bondía (2002) confirma essa prática ao dissertar que "é experiência aquilo que 'nos passa', ou que nos toca, ou que nos acontece, e ao passar nos forma e nos transforma. Somente o sujeito da experiência está, portanto, aberto à sua própria transformação".

É nesse sentido que o objetivo desse trabalho tenta mostrar como o disléxico pode ser inserido no contexto escolar sem que haja exclusões sociais e conteudistas. Porém, a unidade didática descrita não atende somente alunos com dislexia, pois sendo um procedimento de baixo custo e de simples realização possibilita a interação dos alunos em geral, dispostos em grupos ou individualmente. Serve ainda como inspiração a outros professores de Física por ser um trabalho diferenciado em sala de aula que atende às necessidades básicas de aprendizagem.

A unidade didática ocorre por meio da experiência, cujo objetivo é aproximar o aluno da disciplina trabalhada. Bondía (ibid.) faz menção a essa ferramenta metodológica e nota-se, portanto que a experiência, a possibilidade de que algo nos aconteça ou nos toque, requer um gesto de interrupção, um gesto que é quase impossível nos tempos que correm: requer parar para pensar, parar para olhar, parar para escutar, pensar mais devagar, olhar mais devagar, e escutar mais devagar; parar para sentir, sentir mais devagar, demorar-se nos detalhes, suspender a opinião, suspender o juízo, suspender a vontade, suspender o automatismo da ação, cultivar a atenção e a delicadeza, abrir os olhos e os ouvidos, falar sobre o que nos acontece, aprender a lentidão, escutar aos outros, cultivar a arte do encontro, calar muito, ter paciência e darse tempo e espaço.

Vale ressaltar que o caráter da avaliação não será excludente, cujo benefício acarretará em motivação e participação dos alunos facilitando a relação entre a disciplina e o conhecimento a ser adquirido sem exigências, pois o educando não deve 'aprender' por aprender e sim, aprender por prazer, entender, compreender.

O uso do experimento "Ouça seu controle remoto!" para abordar o efeito fotoelétrico abrange conteúdos ocultos à nossa percepção, os quais não são relatados, mas necessários para o entendimento. Por exemplo, nessa atividade pode-se abordar a eletricidade (circuitos elétricos, corrente elétrica, resistores, geradores) e as ondas eletromagnéticas (infravermelho e outras formas de radiação). Esse 
procedimento é apenas mais uma articulação entre diferentes áreas da Física que tem como finalidade trabalhar a visão fragmentada que os alunos têm da disciplina mostrando-lhes a inter-relação de tudo o que os cerca, de modo especial evidenciando os dislexos, estes, portadores de necessidades especiais educacionais amparados por lei.

Diante de tudo, é fato o êxito alcançado por meio de atividades diferenciadas como propõe os PCNs (2002) afirmando que a aprendizagem na área de Ciências da Natureza, Matemática e suas Tecnologias indica a compreensão e a utilização dos conhecimentos científicos para explicar o funcionamento do mundo, bem como planejar, executar e avaliar as ações de intervenção na realidade. É imprescindível abordar cada conteúdo correlacionado a uma experimentação para facilitar a aquisição de conteúdo científico. Para tal ação necessita-se de profissionais preparados para atuar em sala de aula e principalmente, dispostos a conduzir os alunos ao conhecimento; sejam eles portadores de necessidades especiais ou não.

Atividade experimental como recurso para interação de alunos com transtornos específicos de aprendizagem em Física Moderna e Contemporânea. 


\title{
Experimental activity as a resource for interaction of students with specific learning disorders in Modern and Contemporary Physics
}

\begin{abstract}
Learning is a complex process that depends on organic and behavioral factors. In this way, knowing the origin of the learning disorders that have compromised the assimilation of knowledge is important. In this work, the discussion about dyslexia, a learning disorder that leads to difficulties in the development of reading and writing skills, will be emphasized. Dyslexic students present peculiarities in the teaching process and the teacher should promote appropriate pedagogical practices so that they have equity in the teaching process. Realizing the importance of the discipline of Modern Physics in the curriculum of Physics in High School, it is proposed in this work an experimental activity, made with low cost materials, whose approach will be the photoelectric effect. In working the experiment, the teacher can encourage students with dyslexia to investigate what happens during their execution and, through questions, to get them to express their previous ideas in an attempt to explain their functioning.
\end{abstract}

KEYWORDS: Physics. Dyslexia. Experiment. Photoelectric effect. 


\section{REFERÊNCIAS}

BRASIL. Ministério de Educação e Cultura. LDB - Lei no 9394/96, de 20 de dezembro de 1996. Estabelece as diretrizes e bases da Educação Nacional. Brasília: MEC, 1996.

BRASIL. Ministério da Educação. Secretaria de Educação Média e Tecnológica. Parâmetros Curriculares Nacionais (Ensino Médio). Brasília: MEC, 2000.

BORBA, Ana Luiza; BRAGGIO, Mario Ângelo. Como interagir com o disléxico em sala e aula. Disponível em:<http://xa.yimg.com/kq/groups/26822210/1297107516/name/DISL EXIA..pdf.> acesso em 08 de Jan. de 2016.

BONDIA, J.L. Notas sobre a experiência e o saber de experiência. Revista Brasileira. Ed., 19, 20-28, 2002.

CONSELHO NACIONAL DE EDUCAÇÃO. Ministério da Educação. Disponível em:

<http://portal.mec.gov.br/cne/arquivos/pdf/CEB0201.pdf> Acesso em: 09 fev. 2016.

DIRETRIZES CURRICULARES DA EDUCACAO BÁSICA: FISICA. Ministério da Educação. Disponível em: $<$ http://www.educadores.diaadia.pr.gov.br/arquivos/File/diretrizes/dce _fis.pdf> Acesso em: 12 mar.2016

HAYDU, V. B., FORNAZARI, S. A.; ESTANISLAU, C. R.. Psicologia e Análise do Comportamento: Conceituações e Aplicações à Educação, Organizações, Saúde e Clínica. (1. ed.). Londrina: UEL, 2014.

IANHEZ, M. e NICO, M. A. Nem sempre é o que parece: como enfrentar a dislexia e os fracassos escolares. São Paulo: Elsevier, 2002.

MINISTERIO DA EDUCACAO. Citação de referências e documentos eletrônicos. Disponível em:

<http://portal.mec.gov.br/cne/arquivos/pdf/CEB017_2001.pdf > Acesso em: 09 fev. 2016.MOREIRA, M. A. Particulas e Interações. Física na Escola, v. 5, n. 2, 2004. ROTTA, T, N. PEDROSO, S, F. Transtornos da linguagem, in: ROTTA, T, N. 
neurobiológica e multidisciplinar. $2^{\circ}$ edição, Porto Alegre: Artmed, 2007.

SILVA, F; ASSIS A. Física Moderna no Ensino Médio: um experimento para abordar o efeito fotoelétrico. Caderno Brasileiro de Ensino de Fisica, v. 29, n. 2, 2012.

TOZZI, M.; OTA, J. Vertedouro em degraus. Revista da Vinci, Curitiba, v.1, n.1, p. 9-28, 2004.

UNESCO. Declaração de Salamanca. Espanha, Salamanca, 1994.

VICENTER, M. O Direito dos Portadores de Dislexia ao Atendimento Educacional Especial. Disponível em:

http://educacaoonline.pro.br/index.php?option=com_content\&view=ar ticle \&catid $=5 \% 3$ Aeduc acao-especial $\& i d=25 \% 3$ Ao-direito-dosportadores-de-dislexia-ao-atendimento-educacionalespecial\&Itemid=16 Acesso em: 10 fev. 2016.

DOI: 10.3895/rbect.v10n1.5715

Como citar: MONTEIRO, E. L.; FILHO, P. S. C.; GRESCZYSCZYN, M. C. C. Atividade experimental como recurso para interação de alunos com transtornos específicos de aprendizagem em Física Moderna e Contemporânea. Revista Brasileira de Ensino de Ciência e Tecnologia, v. 10, n. 1, 2017. Disponível em: $<$ https://revistas.utfpr.edu.br/rbect/article/view/5715>. Acesso em: xxx.

Direito autoral: Este artigo está licenciado sob os termos da Licença Creative Commons-Atribuição 4.0 Internacional. 